\title{
E1 altruismo en la televisión: economía, ideología y emociones. Caso Teletón 2014
}

\author{
Diana Juárez Torres* \\ Universidad Iberoamericana, Ciudad de México
}

\section{RESUMEN}

El Teletón, evento de recaudación de fondos para niños con discapacidad, ejerce una serie de estrategias discursivas que apelan a las emociones de culpa, miedo, lástima, enojo e ironía para incitar a la donación. Estas estrategias devienen de una base ideológica donde la iglesia, el gobierno y el capitalismo han configurado una comunicación emocional que pretende esconder los vacíos del Estado, en este caso, la pobreza, la corrupción y la falta de regulación de medios, lo que nos deja ver la relación clientelista entre los medios, empresas y gobierno.

Palabras clave: Teletón, discurso, clientelismo, emociones, análisis del discurso

\begin{abstract}
The Teleton, fundraising event for children with disabilities, practices a series of discursive strategies rooted on emotions (guilt, fear, pity, anger, irony) to convince the audience to donate and watch its audiovisual production based on a star system. These strategies descend from an ideological basis built by church, government and capitalism to configure an emotional communication that attempts to bide the gaps of the State, such as poverty, corruption and lack of media regulation. An analysis of Teleton's discourse points towards the clientelistic relations between media, government and private companies in México.
\end{abstract}

Keywords: Teleton, speech, clientelistic, emotions, speech analysis

*Maestra en Comunicación por la Universidad Iberoamericana y Licenciada en Comunicación Social por la Universidad Autónoma Metropolitana, Unidad Xochimilco. Correo electrónico: dianaju.to@gmail.com 
DE QUÉ VA LA INVESTIGACIÓN: OBJETIVO DE INVESTIGACIÓN, PREGUNTA Y SUPUESTO DE PARTIDA

Este artículo surgió de una investigación de posgrado para obtener el grado de maestría. La pregunta general fue ¿Cuáles son las estrategias discursivas que aplica el Teletón para apelar a la lástima y compasión?, de la que surgieron las preguntas secundarias:

-¿Qué oculta el discurso del Teletón?

-¿Qué motiva a la gente a donar al Teletón?

-¿Cómo es la correlación de actores que ejecutan el Teletón?

-¿Qué otros beneficios otorga el Teletón, además de las terapias de rehabilitación?

De las preguntas señaladas se construyó el objetivo general: identificar el papel que juega el uso de las emociones en el Teletón para provocar lástima e incitar a la donación de recursos con el tema de la discapacidad entre la sociedad mexicana.

Se partió de un supuesto donde el discurso emocional utilizado por el Teletón devela aspectos del sistema político actual, puesto que el Estado se deslinda de su responsabilidad social y las empresas se aprovechan de esta situación para mostrarse como socialmente responsables e involucrar a los ciudadanos en la idea de que deben subsidiar esta problemática sin cuestionar que esta falta deviene de un vacío de poder provocado intencionalmente.

Para aseverar este supuesto, primero se hizo un recorrido teórico bajo tres líneas de análisis: ideológico, emocional y de la economía política.

\section{RECORRIDO TEÓRICO DE LA IDEOLOGÍA, EMOCIONES Y ECO- NOMÍA POLÍTICA}

Teun Van Dijk (2006, p. 18) señala que la ideología es un "sistema de creencias" que se desarrolla en tres conceptos: cognición, sociedad y discurso. El concepto de cognición se comprende como el campo simbólico del pensamiento y las creencias en donde pertenece el sistema de ideas. Del segundo aspecto advierte que las ideologías son de carácter social y con frecuencia están asociadas a intereses, conflictos y luchas de grupo. En lo que se refiere al uso del lenguaje o el discurso, el ocultamiento, la legitimación, la manipulación y otras nociones relacionadas que se consideran como las funciones primordiales de las ideologías en la sociedad son, sobre todo, prácticas sociales discursivas (o semióticas en un sentido más amplio).

A partir de este planteamiento se entien- 
den a los discursos como formas de acción e interacción social, situados en contextos donde los participantes no solo son hablantes, escritores, oyentes o lectores, sino también actores sociales. El análisis crítico del discurso permite conocer como se ejercen las relaciones de poder (Van Dijk, 2006) y ver lo que ha estado oculto, recordar un pasado. Es entonces que la "crítica" hace visible la interacción de las cosas (Wodak y Meyer, 2003).

Desde la perspectiva emocional, se parte de la mirada construccionista donde se asume que las emociones son adquiridas y están determinadas por un sistema de creencias. Esta perspectiva es desarrollada por Berger, Luckman (1966) y Harré (1986), quienes entienden a las emociones como una construcción social a partir de dos perspectivas: a través del tiempo (perspectiva histórica) las emociones se van configurando a partir del lenguaje (perspectiva discursiva).

Rodrigo Alsina (1993) completa el estudio del enfoque construccionista, con la perspectiva teórica del "interaccionismo simbólico", la cual está relacionada con la antropología y la psicología social. Ésta se refiere a la construcción de significados a partir de la interacción con los otros, determinada por nuestra relación con los objetos, los cuales también tienen su propio significado dado por los sujetos.
La economía política se entiende desde el planteamiento de César Bolaño (2016) y Manuel Alejandro Guerrero (2014), como la relación entre instituciones privadas y públicas con el Estado y los medios de comunicación. Bolaño (2016) señala, en una entrevista, que la importancia del estudio de la economía en la comunicación radica en entender la producción humana (que deviene de la cultura y comunicación) dentro de las estructuras de poder. "La comunicación es una estructura de poder y por tanto, en cualquier sociedad, quien controla la comunicación interviene en una esfera de poder importante. Los estudios de comunicación también están influenciados por las disputas de poder que existen a nivel de la sociedad", comentó el investigador a un medio latinoamericano (Ramón, 2015).

En conferencia, Bolaño (2015) señaló que la comunicación es una estructura de poder $y$, por tanto, analizar a los medios desde la economía política nos permite ver sus relaciones con el Estado y las empresas para producir propaganda y publicidad. Perspectiva que nos ayudará a entender la importancia de la correlación de funcionarios públicos y directivos de corporativos en el Teletón.

En concordancia con la relación de empresas, medios y gobierno, el investigador Manuel Alejandro Guerrero (2014) ha desarro- 
llado la figura "clientelista", que se refiere a la relación directa de los medios con los procesos políticos y las alianzas con ciertos grupos de poder, lo que reduce la efectividad de la regulación y crea condiciones que irrumpen el ejercicio profesional de los medios para informar a la ciudadanía.

Para entender la importancia de la mediatización del poder, se retoman los planteamientos de Balandier (1994), Debray (1993) y Debord (1976). Georges Balandier (1994), señala que las relaciones de poder y dominación están regidas por una tríada: información, comunicación y técnica, "a ésta deberá atribuírsele todo cuanto el poder ha recibido de trascendencia, de lo sagrado y de la historia... Los lenguajes, las simbolizaciones y las imágenes, las ritualizaciones y las dramatizaciones se adaptan a sus imperativos y actúan bajo su influencia" (p. 12), es decir, lo político ha quedado subordinado por lo mediático.

Esta necesidad de mediatización se comprende porque "nadie ha visto nunca un Estado. Ni a simple vista ni en el microscopio, ni en foto ni desde un avión. No es una cosa, como un territorio o como una porción de océano. ¿Qué es el Estado? El Estado no tiene forma ni imagen en sí, ni siquiera un país ¿̇ alguna vez se le ha visto?" (Debray, 1993 p. 59). Incluso, tampoco tienen forma las empresas, instituciones o religiones, éstas se construyen a través de ideas o símbolos.

El poder se ha esforzado más por un hacer ver que por un hacer pensar, provocando que los ciudadanos se conviertan en espectadores. La sociedad se ha reducido a un "espectáculo", que para Guy Debord (1976, p. 7) “no es conjunto de imágenes, sino una relación social entre personas mediatizada por imágenes. La vida de las sociedades se anuncia como una inmensa acumulación de espectáculos".

Dentro de esta espectacularización de la sociedad destaca la televisión, la cual demostró ante el cine su capacidad para crear celebridades que podían influir en las audiencias, sin recurrir a las estrellas del séptimo arte. A esta producción de personajes se ha denominado star-system, "la sustitución de la persuasión racional por el carisma telegénico (que es un valor con componentes básicamente emocionales, desde los eróticos a los paternalistas)" (Gubern, 1987, p. 374).

En concordancia, Gubern (1987) señala que donde haya glamur se debe sospechar de una apatía del espectador. Es así como sucede en el Teletón, donde se abusa del espectáculo pese a la situación delicada de los niños con discapacidad, para incentivar el interés del televidente.

Uno de los mecanismos que se han iden- 
tificado como instrumento del poder es el "altruismo", bandera con la que navega el Teletón. De acuerdo con Zizek (2011) el altruismo es un valor simbólico dentro del capitalismo que se refuerza con un consumo aparentemente "libre de culpas". Naomi Klein (2007) describe a la responsabilidad social como un aprovechamiento del poder de las empresas y el Estado, este vacío aparentemente resuelto por la caridad de los donantes en algunas ocasiones es provocado por lo que deja de hacer el Estado.

\section{METODOLOGÍA}

Para identificar las estrategias discursivas, se realizó un análisis de discurso basado en la metodología de J.B. Thompson (2002) que consta de tres etapas: sociohistórica, discursiva y de re-interpretación. En la primera se intentó "reconstruir las condiciones sociales e históricas de la producción, circulación y recepción de las formas simbólicas" (p. 409), es decir, se analizaron los actores involucrados con el Teletón.

En la segunda, la discursiva, que en sí es el análisis del discurso, se construyó a partir de tres propuestas teóricas. El método de análisis está basado en el modelo de Casseti y Di Chio (1999), compuesto por tres códigos: los de la realidad se refieren al mundo que presenta la televisión; los discursivos al modo en que el aparato televisivo representa al mundo y los ideológicos, como el nombre lo refiere, el análisis de la ideología, el cual se enriqueció con el método semiótico y argumentativo. En el análisis semiótico se retomó la propuesta de Stuart Hall (1972) sobre los códigos dominante-hegemónico, profesional de oposición. Y en el argumentativo, se retomaron los cinco modos de operación de la ideología que propone J.B. Thompson (2002): legitimación, simulación, unificación, fragmentación y codificación.

La configuración de este método permitió el análisis a nivel audiovisual y textual de cinco unidades de análisis en la tesis de posgrado, que para este artículo solo se presentan dos unidades de la emisión del Teletón de 2014: el monólogo de apertura que hizo el conductor Eugenio Derbez, que se distinguió por pedir a la audiencia olvidar la desaparición de los 43 estudiantes de la Normal de Ayotzinapa al tiempo que recomendó mejor preocuparse por los niños con discapacidad que atiende el Teletón.

La segunda fue el discurso previo al cierre de la programación dado por Derbez, donde responde a las redes sociales quienes lo acusan de seguir un guión, mientras reprende a la sociedad mexicana por no ser sensible "al 
mejor programa de ayuda social que tiene México": el Teletón. Su importancia radica en que se establece una reacción de los medios tradiciones ante las redes sociales.

\section{ANÁLISIS}

\section{Contextual}

Se encontró que las organizaciones altruistas surgen en México en la época colonial, de acuerdo a la investigación de Von Wobeser (2010). Las donaciones fungieron un papel importante, ya que solventaron la crisis financiera del periodo. Con el dinero o bienes inmuebles donados se crearon fundaciones piadosas que podían relacionarse con los negocios, préstamos, inversiones de capital, quiebras o ventas. Las donaciones, en aquella época, eran conocidas como indulgencias, realizadas por la población adinerada, "los motivos religiosos, que eran muy poderosos, se creía que por medio de las obras de caridad se podía lograr la salvación eterna” (p. 780).

La práctica de apropiarse de terrenos y herencias que realizó la Iglesia en la época colonial fue adoptada por Marcial Maciel, fundador de los Legionarios de Cristo y del movimiento Regnum Christi, donde miles de católicos entregaron su vida al servicio de los demás y aportaron su dinero con la convicción de que sería utilizado para causas nobles. Al respecto, Raúl Olmos (2015), en su libro El imperio financiero de los Legionarios de Cristo señala: "con engaños, Maciel arrebató las herencias de las viudas, constituyó decenas de empresas fantasma que carecían de instalaciones, oficinas, y empleados y recurrió a paraísos fiscales para evadir impuestos y lavar dinero" (p. 15).

De acuerdo con el historiador González Navarro (1985), "en la historia de las sociedades regidas por la desigualdad, primero se crea a los pobres y después los asilos, los hospicios y los hospitales. Don Hernán Cortés conquistó primero a los indios y después fundó el Hospital de Jesús. Don Pedro Romero de Terreros primero se convirtió en el hombre más rico de su época con la explotación de los mineros y de la plata y después creó el Monte de Piedad" (p. 175). La relación entre la creación de necesidades de la población e instituciones de asistencia es de larga trayectoria.

Si atendemos casos históricos se observa que ha existido un aprovechamiento de la situación de pobreza del país. En México, casi la mitad de la población, 46.2\% es decir 55.3 millones de personas, se encuentran esta situación, de acuerdo con el Coneval, por lo que se estima que la cifra vaya en aumento; de acuerdo a la Comisión Económica para América Latina y el Caribe (Cepal), en México junto

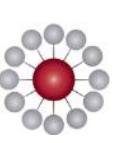


con Guatemala y Venezuela, la pobreza creció en 2014 y 2015. Cabe señalar que las principales causas de la discapacidad están relacionadas a las condiciones de pobreza, por ejemplo: mala alimentación, falta de acceso a servicios médicos, condiciones de trabajo peligrosas, tales como laborar en una fábrica, mina, campo agrícola o que la madre esté en contacto con sustancias químicas; el consumo de drogas o medicinas sin prescripción médica; accidentes nucleares y la guerras civiles.

\section{Fundación Teletón}

Para entender la relación entre la pobreza, la Iglesia y el Teletón, falta mencionar cómo fue la llegada del Teletón a México. Este proyecto lleva 19 años de transmisión en el país. Surgió como inspiración del proyecto de Jerry Lewis (MDA Labor Day Telethon, 1952). En América Latina, la primera versión se realizó en Chile (1978) por el presentador Don Francisco (Mario Kreutzberger), quien actualmente es representante de la Organización de Teletones que agrupa a varios países de Latinoamérica y el Caribe.

La Fundación Teletón nació en 1997 con dos socios: México Unido (propiedad de los Legionarios de Cristo) y Televisa, dio inicio con una aportación de 100 mil pesos. El proyecto ha sido liderado por el ex seminarista de los Legionarios Fernando Landeros, que hasta la fecha es presidente de la Fundación, apoyado desde entonces por Emilio Azcárraga Jean, otro legionario.

Para sostener a la Fundación Teletón se han creado varias asociaciones, también se han formalizado alianzas con empresas y medios de comunicación, y se han pactado convenios con el Estado, formalizados desde el Congreso, tal como se dio a conocer en 2016 cuando Fernando Landeros denunció en entrevista con Ciro Gómez Leyva que no había recibido el pago comprometido por los gobernadores Roberto Borge (2010-2016) en Quintana Roo, Javier Duarte (2010-2016) en Veracruz y César Duarte en Chihuahua (2010-2016), lo que podría provocar el cierre de los centros de rehabilitación. Lo destacable es que estos tres gobernadores han sido catalogados de corruptos. En la entrevista, Landeros señaló que cuando se pacta la creación de un Teletón, la administración del Estado debe ceder un terreno y pagar un convenio por 10 años. Sobre esta alianza entre Televisa y el Estado, Clara Jusidman, ex secretaria de Desarrollo Social en el DF, dijo: "El Teletón se ha convertido en un monopolio privado con ayuda de los dineros públicos".

En una entrevista realizada por el investigador Ernesto Villanueva (2014) de la 
UNAM a un gobernador, cuyo nombre no es revelado, éste responde:

Si el Estado aporta al Teletón terrenos, deducibilidad de impuestos estatales y municipales, además de dinero, vamos a tener una presencia en Televisa que de otra forma no tendríamos. Incluso si yo pido a empresarios locales apoyo para un centro parecido al Teletón, no me van a donar nada por la cultura de la desconfianza, pero con el Teletón obtienen sus recibos de deducibilidad y son mencionados, por lo que encuentran más atractivo ayudar de esa manera.

En 2014 la Organización de las Naciones Unidas, en el marco del año de la discapacidad, hizo una serie de observaciones al gobierno de México entre las que destacaron: no estereotipar a las personas con discapacidad y no destinar recursos públicos a proyectos privados. Señalamientos que se dijo afectaron al Teletón, sin embargo, Raúl Olmos (2015) aseveró en su investigación que fue uno de los mejores años para la Fundación: "Los conductores de Televisa recurrieron al drama antes de anunciar la cifra que ya tenían previamente comprometida" (p. 199). Carlos Loret de Mola comentó en la transmisión "Sí, fue el Teletón más difícil", lo que Landeros confirmó. La cifra que se anunció fue de 474 millones 143 mil 221 pesos, y a Hacienda se reportaron dos mil 497 millones de pesos, cinco veces más del monto que se anunció.

\section{Discurso}

Las unidades de discurso que se analizaron fueron el monólogo de bienvenida y despedida de Eugenio Derbez, conductor del programa. En el análisis de códigos de la realidad se encontró que los movimientos de cámara eran muy lentos, los encuadres iban del full shoot al medium shoot. En el ambiente sonoro solo se escuchaba la voz de Derbez y en algunas ocasiones los aplausos del público.

En el análisis de los códigos discursivos, en la primera pieza se destacó la mención sobre el impacto en redes sociales, la transparencia del Teletón al invitar a las audiencias a visitar los Centros de Rehabilitación, el pago de la "casa blanca" de Angélica Rivera y la desaparición de los 43 normalistas de Ayotzinapa.

Algunos fragmentos del discurso de esta primera intervención fueron:

Quiero extender de manera muy personal, algunos puntos que se han estado comentando mucho en las redes sociales y que creo yo, no podemos ignorar. Por ejemplo, ha habido muchas críticas del Teletón, cuestionando la transparencia del Teletón o que si esto es una estrategia de Televisa para pagar menos impuestos. Vaya hasta se ha co- 
mentado que la lana se utilizó para construir una mansión en las lomas.

Un segundo extracto del discurso:

Nos hemos unido para darle voz a esos 43 jóvenes que seguimos esperando a que aparezcan. ¡Ahí voy, ahí voy! ¡Sí, ya saben cómo me pongo, pa'que me invitan! (...)Lo que no está bien es que por el coraje que todos traemos con justa razón nos llevemos entre las patas a todos esos niños que dependen del Teletón. México está pasando por un momento muy fuerte y muy difícil, y es precisamente ahora que tenemos que unirnos no solo para gritar "iya me cansé!"

En la segunda unidad de análisis el discurso de Eugenio Derbez responde a la viralización de comentarios en redes sociales, los cuales critican la transparencia del Teletón, y apela a la labor altruista que tuvo la sociedad civil en el terremoto de 1985. Algunos extractos:

Yo siempre he estado muy orgulloso de México, de su gente, porque siempre hemos sido de esos que cuando hubo un terremoto nos unimos. De esos que cuando hubo un huracán, nos unimos. De que sin importar clases sociales, ni religión, ni creencias políticas, simplemente nos uníamos para tenderle la mano a otro mexicano, y hoy estamos
Diana Juárez Torres

tan enojados, tan ocupados en otras cosas, que ya se nos olvidó ser así.

Yo le pregunto a la gente de las redes sociales por qué hoy es más fácil creerle a un desconocido amparado en el anonimato, que a todos los que hoy sí hemos venido a dar la cara (en esta parte de su discurso hace uso del modo de fragmentación con la estrategia de exclusión del otro).

En el análisis de los códigos ideológicos, de la propuesta planteada por Stuart Hall (2004), predominó el dominante-hegemónico, y el profesional solo cuando menciona el caso de los 43 estudiantes desaparecidos y la compra de la "casa blanca". En los que respectan a la propuesta de J.B. Thompson (2002), en ambas piezas destacaron los de legitimación, fragmentación y unificación.

En el modo de legitimación, Derbez aplicó las siguientes estrategias:

-Racionalización, al mencionar los logros de la Fundación Teletón como construcción de los 21 Centros de Rehabilitación y atención médica a más de 80 mil niños y niñas con discapacidad, autismo o cáncer.

-Universalización, al generalizar que todos los niños de México con discapacidad son atendidos por el Teletón, y este argumento es suficiente para que la sociedad mexicana crea y done. 
-Narrativización, mencionó la desaparición de los 43 estudiantes desaparecidos de Ayotzinapa y la compra de la "casa blanca" para justificar que Televisa sí cubrió esos eventos, pero que no por ello la audiencia debe detener su causa hacia los niños con discapacidad.

-Cosificación, con la estrategia de naturalización al asumir la violencia, falta de transparencia y corrupción que existen en México, como actos cotidianos. Incluso, tomó como normal los cuestionamientos que se hacen al Teletón, y declaró que él también los tuvo.

El conductor utilizó el modo de unificación con la estrategia de simbolización de la unidad al referirse al Teletón como un símbolo nacional y dijo que "es de todos los mexicanos" porque todos la construyeron y es la causa que los une. Ante esto, se observa que Televisa intenta legitimarse bajo el discurso patriótico.

Además, en la segunda intervención, Derbez aplicó la estrategia de narrativización. Al recordar el terremoto de 1985 y la tragedia de “el huracán”, sin especificar cuál de todos, con el objetivo de apelar a la sociedad civil que se activa en los desastres naturales.

Después de invocar a la unidad nacional, de forma contradictora aplicó la estrategia de fragmentación, al dividir a la población entre quienes usan las redes sociales y quienes no; entre quienes apoyan al Teletón y quienes no. Algunos extractos de su discurso:

\begin{abstract}
Esto se debe a que muchos mexicanos que en años anteriores habían donado hoy no lo hicieron y por lo visto hoy hay mucha gente que no va a donar. (...)Incluso hay gente que anda circulando un contrato, pero yo digo, a ver los que no hablan, por qué se quedan callados, saben a quién van a castigar con su odio, a los niños.
\end{abstract}

\section{Re-interpretación}

La práctica de donar se incorporó al imaginario social desde la época colonial, donde más allá de un acto altruista se entendió como un acto de salvación, por lo que ha prevalecido en la cultura mexicana, y ahora, aprovechada por los Legionarios de Cristo. En un principio se hizo para resolver la crisis financiera, ahora se ha convertido en un modelo de negocio.

Eugenio Derbez intentó responsabilizar a la audiencia de satisfacer las necesidades de las personas con discapacidad. Además aprovechó el sentido nacionalista de los mexicanos, diciendo que al ayudar se unían como nación. Ante esto, se observó que el conductor no invitó al cuestionamiento de dónde están los recursos públicos que deben cubrir estos gastos y sobre todo, no señaló que uno de los factores que está ligado a la discapacidad es la 
pobreza, ya sea porque las madres no se alimentan bien, las familias no tienen los recursos para cuidar de forma adecuada a los niños, entre otras causas que ya se mencionaron.

Respecto a la emisión del Teletón 2014, se dijo ser un año difícil para la Fundación por el cuestionamiento de la transparencia del manejo de sus recursos en redes sociales y las recomendaciones que hizo la Organización de las Naciones Unidas. Sin embargo, Raúl Olmos (2015) comprobó que este año fue de los mejores para el Teletón, por lo que se puede intuir que fue una estrategia de la Fundación para obtener más recursos.

En el análisis del discurso se encontró que el conductor tendió a engrandecer al Teletón con la mención de sus cifras, en cuanto al número de Centros de Rehabilitación construidos y niños atendidos. Cifras que se dijeron de forma aislada, sin comparar con cuántos otros niños dejan de ser atendidos, ya que el Estado se encarga de mantener los centros de la Fundación en detrimento de los hospitales públicos, que se quedan sin recursos.

\section{CONCLUSIONES}

De la pregunta planteada, ¿Cuáles son las estrategias discursivas que aplica el Teletón para apelar a la lástima y compasión?, en el discurso analizado se encontró que Eugenio Derbez apela al senti- miento "nacionalista", el cual ha caracterizado a los mexicanos. De forma sutil, también apeló a la culpa, sentimiento infundado por la ideología católica.

La tercera estrategia encontrada fue la lástima, al hacer ver a los niños con discapacidad como víctimas que necesitan ayuda y no como agentes que puede exigir al Estado que cumpla con la satisfacción de sus necesidades.

La cuarta estrategia - y la más sobresaliente- fue la ironía, con la que Eugenio Derbez intentó conectarse con el enojo de la sociedad mexicana ante la corrupción de las autoridades. De forma sarcástica, cuestionó al gobierno mexicano sobre el tema de la "casa blanca" y la desaparición de los 43 normalistas de Ayotzinapa, pero lo hizo sin profundizar en datos verificables.

También se encontró que la Fundación intentó victimizarse al decir que la emisión 2014 fue el año más difícil; esto no fue por la falta de donaciones, sino otro factor que indirectamente la afectó: la baja en contratos de publicidad que ha tenido la televisión debido a la regulación de la transmisión de publicidad en horarios infantiles y la emigración de éstos a las plataformas over-the-top. Así que ni las redes ni la crisis de la televisión, como se llegó a pensar, causaron el problema del Teletón, porque no hubo mengua en la recaudación. 
Esta estrategia de victimización también la aplicó Fernando Landeros al denunciar a los gobiernos que no pagaron la cifra pactada, lo que evidenció la dependencia de la Fundación de los recursos públicos y por tanto, la relación clientelista que sostiene el Teletón con las empresas y el Estado, donde el telemaratón funge como una plataforma mediática en que los gobiernos ejercen propaganda política y los empresarios publicidad. Hallazgo que responde a la pregunta ¿Qué oculta el discurso del

\section{Teletón?}

Ante el cuestionamiento ¿Qué motiva a la gente a donar al Teletón?, influyeron las estrategias discursivas encontradas, además de las imágenes estereotipadas que utilizó el Teletón, lo que refuerza la idea desarrollada por algunos investigadores, donde los ciudadanos se han convertido en consumidores, aseveración que ilustra el concepto de Guy Debord (1967) sobre "la sociedad del espectáculo", ya que al ayudar al Teletón hay una posibilidad de aparecer en la televisión.

A esto, el mismo Debord (1967) ha aseverado que la sociedad se relaciona con per- sonas mediatizadas por imágenes, y todo lo aparentemente importante se ve a través de la pantalla, es por ello que el concepto star system de Gubern (1987) retoma fuerza, ya que las celebridades creadas por la televisión tienen una gran capacidad de influir en las audiencias, así que el discurso en voz de Eugenio Derbez tiene mayor impacto.

La articulación mediática del Teletón nos deja ver que prevalece una sociedad espectadora carente de crítica y acción, que antes que ciudadana es un ente consumidor que solo aprueba o desaprueba. Y deja fuera el cuestionamiento de dónde quedan los otros niños que no son atendidos, qué pasa con los recursos públicos, por qué el Estado dona a iniciativas de empresas privadas.

Este análisis también dejó ver una falta de regulación de medios en la cuestión de inclusión, ya que no hay contenidos dirigidos a personas con discapacidad, mucho menos espacios donde ellos puedan participar como emisores, ni contenidos que sensibilicen a la población en general ante la cultura de la discapacidad. 


\section{FUENTES CONSULTADAS}

Alsina, M. R. (1993). Per a una analisi constructivista del discurs emotiu. Cataluña, España. Recuperado el 10 de junio del 2015 de http://www.raco.cat/index.php/analisi/article/viewFile/41178/89137.

Balandier, G. (1994). El poder en escenas, de la representación del poder al poder de la representación. Barcelona, España: Paidós.

Berger. P.L. y Luckman, T. (1966). La construcción social de la realidad. Argentina: Amorrortu Editores.

Bolaño, C. (2016). "Seminario de Economía Política”. Ciudad de México: Universidad Iberoamericana.

Cassetti, F. y Di Chio, F. (1999). Análisis de la televisión. Instrumentos, métodos y prácticas de investigación. Barcelona, España: Paidós.

Debray, R. (1993). El Estado seductor. Argentina: Manantial.

Debord, G. (1967). La sociedad del espectáculo. París: Naufragio.

Gubern, R. (1987). La mirada opulenta. Barcelona, España: Gustavo Gili.

Guerrero, M. y Márquez-Ramírez, M. (ed.) (2014). Media systems and communication policies in Latin America. México: Palgrave.

González, N. (1985). La pobreza en México. El Colegio de México. Recuperado el 13 de abril del 2017 de http://historiamexicana.colmex.mx/index.php/RHM/article/viewFile/1891/1709.

Hall, S. (1972). "Encoding / decoding. Culture, media, language". En: Working Papers in Cultural Studies. Londres. Recuperado el 11 de enero del 2014 de faculty.georgetown.edu/irvinem/theory/SH-Encoding-Decoding.pdf.

Harré, R. (1986). The social construction of emotions. Recuperado el 20 de abril del 2014 de https://es.scribd.com/document/130919408/Harre-1986-review.

Klein, N. (2007). Teoría del shock. Argentina: Planeta.

Olmos, R. (2015). El imperio financiero de los Legionarios de Cristo. Ciudad de México: Grijalbo.

Ramón, M. (2015). César Bolaño: pensar la comunicación desde la economía política. Recuperado 15 de junio del 2017 de

www.cubadebate.cu/noticias/2015/12/10/cesar-bolano-pensar-la-comunicacion-desde-la-economia -politica/.

Thompson, J.B. (2002). Ideología y cultura moderna. Teoría crítica social en la era de comunicación de masas. México: UAM. 
Van Dijk, T.A. (2006). Idelogía. Una aproximación multidisciplinaria. Sevilla, España: Gedisa.

Von Wobeser, G. (2012). "Certezas, incertidumbres y expectativas en torno a la salvación del alma. Creencias escatológicas en Nueva España, siglos XVI-XVIII”. En: Historia Mexicana, 61(4), 1311-1348. Recuperado de historiamexicana.colmex.mx/index.php/RHM/article/view/222/199.

Villanueva, E. (2014). “Teletón: caridad y discriminación”. En: Proceso, Ciudad de México, 11 de octubre de 2014. Recuperado el 11 de enero del 2016 de www.proceso.com.mx/384514/teleton-caridad-y-discriminacion.

Wodak, R. y Meyer, M. (2003). Métodos de análisis crítico del discurso. Barcelona, España: Gedisa.

Zizek, S. (2011). Primero como farsa y después como tragedia. Recuperado el 12 de marzo del 2014 de https://kabirabud.files.wordpress.com/2013/10/c5beic5beek-s-primero-como-tragedia-despues-c omo-farsa-2011.pdf. 